Original Article

\title{
DESIGN AND EVALUATION OF MODIFIED CHITOSAN BASED IN SITU GEL FOR OCULAR DRUG DELIVERY
}

\author{
ANUJA T. KADAM ${ }^{*}$, RAHUL L. JADHAV ${ }^{1}$, PRADNYA B. SALUNKE ${ }^{2}$, SATWASHILA S. KADAM ${ }^{3}$ \\ ${ }^{1,3}$ Late Narayandas Bhawandas Chhabada Institute of Pharmacy, Raigaon, Satara 415020, Maharashtra, India, ${ }^{2}$ Gourishankar Institute of \\ Pharmaceutical Education and Research, Limb, Satara, Maharashtra, India \\ Email: anujakadam04@gmail.com
}

Received: 24 Jun 2017 Revised and Accepted: 21 Sep 2017

\section{ABSTRACT}

Objective: The object of the present study was to formulate and evaluate in-situ gel of modified chitosan by using temperature triggered method to improve bioavailability.

Methods: Modified chitosan-based moxifloxacin $\mathrm{HCl}$ was prepared by cold method. polaxomer 407 adding in distilled water and this solution kept in the refrigerator. Modified chitosan and moxifloxacin $\mathrm{HCl}$ was dissolved separately in distilled water and added to the polymeric solution with continuous stirring until thoroughly mixed. Prepared formulation was evaluated for drug content, gelling capacity, rheological study, in vitro drug release behavior, measurement of phase change temperature, antibacterial study, release kinetics, statistical analysis.

Results: The prepared formulations were evaluated for their, drug content, gelation temperature, in vitro drug release studies, rheological study and release kinetics. All batches of in situ formulations had satisfactory $p \mathrm{H}$ ranging from $6.2 \pm 0.2$, drug content between $98.8 \pm 0.2$ showing uniform distribution of drug. As the concentration of each polymeric component was increased, there was a decrease in phase change temperature. The in vitro drug release decreased with increase in polymeric concentrations. The antibacterial efficiency of the selected formulation against staphylococcus aureus confirmed that designed formulation has prolonged effect and retained its properties against bacterial infection.

Conclusion: The prepared in situ gelling formulation had the appropriate combination of polaxomer 407 and modified chitosan were suitable satisfactorily sustained the drug release from moxifloxacin $\mathrm{HCl}$ in situ gel. The prepared formulation of moxifloxacin $\mathrm{HCl}$ appears to be promising drug delivery for bacterial infectious disease.

Keywords: Ocular drug delivery, In situ gel, Modified chitosan, Polaxomer 407, Moxifloxacin HCl

(C) 2017 The Authors. Published by Innovare Academic Sciences Pvt Ltd. This is an open-access article under the CC BY license (http://creativecommons.org/licenses/by/4.0/) DOI: http://dx.doi.org/10.22159/ijpps.2017v9i11.20938

\section{INTRODUCTION}

The current situation of ophthalmic drug delivery is highly competitive and rapidly developing. The conventional ocular drug delivery systems like solutions, suspensions and ointments have drawbacks such as increased precorneal elimination, high changeability and blurred vision, low residence time. Poor bioavailability of drugs from ocular dosage forms is mainly due to tear production, transient residence time and impermeability of corneal epithelium [1]. Several in situ gelling system have been developed to prolong the precorneal residence time of a drug and improve ocular bioavailability. These systems consist of polymers that exhibit sol to gel phase transitions due to change in specific physicochemical parameters $(p \mathrm{H}$, temperature $)$ in their environment, the cul-de-sacin this case [2]. Chitosan is a biodegradable polymer that has demonstrated excellent ocular compatibility. Chitosan solutions have been successfully used in prolonging contact time with the ocular surface. Therefore, a combination of this polymer with poloxamer would be very promising for ocular administration, as the in situ mechanical strength of the formulation would be higher than that of both polymers alone [3]. The aim of the present work was to obtain an ophthalmic delivery system with improved retention time for the treatment of ocular diseases.

\section{MATERIALS AND METHODS}

\section{Materials}

Moxifloxacin $\mathrm{HCl}$ was received as gift sample from Emcure Pharmaceutical Hinjavadi, Pune. Modified chitosan was purchased from Sea Foods Kochi, India. Polaxomer 407 was purchased from S D Lab Chem, Mumbai. All other chemicals used were of analytical grade. Freeze-dried strains staphylococcus aureus was obtained from Yashvantrao Chavan Institute of Science, Satara.

\section{Methods}

Preparation of in Situ gel formulation

In situ gel was prepared by the cold method. A weighed amount of polaxomer 407 was slowly added to $15 \mathrm{ml}$ distilled water (at $4 \pm 2{ }^{\circ} \mathrm{C}$ ) in a beaker with continuous stirring using a magnetic stirrer at a speed of $500 \mathrm{rpm}$ for $2 \mathrm{~h}$. The temperature of the water was maintained at $4 \pm 2{ }^{\circ} \mathrm{C}$ throughout the preparation. This solution was kept overnight in a refrigerator at $4{ }^{\circ} \mathrm{C}$ results in clear solution. Modified chitosan was initially dissolved in distilled water and it is then kept in the refrigerator and then it is added to the above solution. Moxifloxacin $\mathrm{HCl}$ was weighed separately and dissolved in distilled water and added to the polymeric solution with continuous stirring until thoroughly mixed. Benzalkonium chloride $(0.01 \%)$ was added as a preservative. Finally, the volume was adjusted with distilled water up to $50 \mathrm{ml}$. The composition of the in situ gel formulations is shown in table $1[4,5]$.

\section{Evaluation}

Drug content

Drug content of moxifloxacin $\mathrm{HCl}$ was determined by taking $1 \mathrm{ml}$ sample of in situ gel into $100 \mathrm{ml}$ volumetric flask and diluting with $100 \mathrm{ml}$ of simulated tear fluid then analyzed using UV-visible spectrometer at $287 \mathrm{~nm}$ [6].

\section{Determination of $p H$}

The $p H$ of the gel was determined using calibrated $p H$ meter. Determinations were carried out in triplicate and an average of these determinations was taken as the $p H$ of the gel [7].

\section{Measurement of phase change temperature}

The gelation temperature was determined by placing the $2 \mathrm{ml}$ cold sample solution in the test tube was dipped in a water bath whose 
temperature was maintained at $37 \pm 5{ }^{\circ} \mathrm{C}$ for $2 \mathrm{~min}$. The temperature at which solution was converted to gel was noted down by placing the thermometer in the test tube. The maximum limit for gelation was checked up to $60{ }^{\circ} \mathrm{C}$. The gel was said to have formed when there was no flow of the formulation. Each sample was measured in triplicate [8].

Table 1: Composition of in situ gel formulations

\begin{tabular}{|c|c|c|c|c|}
\hline Formulation code & Drug(g) & Polaxomer(g) & Modified chitosan(g) & Distilled water(ml) \\
\hline F1 & 0.250 & 7 & 0.25 & 50 \\
\hline $\mathrm{F} 2$ & 0.250 & 7 & 0.5 & 50 \\
\hline F3 & 0.250 & 7 & 0.75 & 50 \\
\hline $\mathrm{F} 4$ & 0.250 & 8 & 0.25 & 50 \\
\hline F5 & 0.250 & 8 & 0.5 & 50 \\
\hline F6 & 0.250 & 8 & 0.75 & 50 \\
\hline F7 & 0.250 & 9 & 0.25 & 50 \\
\hline F8 & 0.250 & 9 & 0.5 & 50 \\
\hline F9 & 0.250 & 9 & 0.75 & 50 \\
\hline
\end{tabular}

Number of experiments $=9$

\section{Determination of gelling capacity}

The gelling capacity of the prepared formulation was determined by placing a drop of the formulation in a vial containing $2 \mathrm{ml}$ of freshly prepared simulated tear fluid and visually observed. The time taken for its gelling was noted [9].

\section{Rheological studies}

Viscosity of the instilled formulation is an important factor in determining residence time of drug in the eye. The prepared solutions were allowed to gel at physiological temperature and then viscosity was measured at $37^{\circ} \mathrm{C}$ using Brookfield viscometer model in spindle number 62 at $100 \mathrm{rpm}$. The average of three determinations was taken [10].

\section{In vitro drug release study}

The dialysis bag method was used for in vitro studies. The In vitro release rate of moxifloxacin $\mathrm{HCl}$ from sustained release in situ gel was performed in USP apparatus paddle method with STF ( $p H 7.4)$ as dissolution medium by using $2 \mathrm{~cm}$ diameter cylinder test tubes open at both ends for placing test sample under study. Dialysis membrane previously soaked for $8 \mathrm{~h}$ in STF (simulated tear fluid $p H$ 7.4) was tied to one end of the glass cylinder and $2 \mathrm{ml}$ volume of the formulation was accurately weighed and placed. The glass cylinder was attached to the shaft of USP apparatus, in the place of the paddle. The cylinder was the suspended in $100 \mathrm{ml}$ of dissolution medium and the stirring rate was maintained at $50 \mathrm{rpm}$. The samples were withdrawn from release media at intervals of $1,2,3,4$, $5,6,7,8$ and 9 replaced with an equal volume of fresh STF. The concentration of moxifloxacin $\mathrm{HCl}$ was determined by UV spectrophotometer at $287 \mathrm{~nm}$. The percentage of cumulative release was calculated and a graph of percent cumulative release against time was plotted [11].

\section{Antibacterial study}

The sustained release in situ gel of moxifloxacin $\mathrm{HCl}$ was subjected to antibacterial studies by agar cup plate method. A sterile solution of marketed moxifloxacin $\mathrm{HCl}$ eye drops $(0.2 \mathrm{mg} / \mathrm{ml})$ was used as a standard. The strain of staphylococcus aureus was obtained from the department of microbiology Yashvantrao Chavan Institute of Science, Satara. This study was performed using staphylococcus aureus for antibacterial studies. Three samples tested for minimum inhibitory concentration, and they are standard, modified chitoson and F5 formulation. The nutrient agar media $(25 \mathrm{ml})$ was prepared and sterilized by autoclaving at $121{ }^{\circ} \mathrm{C}, 15 \mathrm{lbs}$ pressure for $15 \mathrm{~min}$. immediately $25 \mathrm{ml}$ of the agar suspension was poured into petriplate. After solidification of the media, the seeded test organism spread on the solid media using a spreader. Three cups of $5 \mathrm{~mm}$ diameter were made using sterile borer. The aliquot test samples were poured to cup aseptically and labeled accordingly. After allowing diffusion of the solution for $2 \mathrm{~h}$, the plate was incubated at $37{ }^{\circ} \mathrm{C}$ for $24 \mathrm{~h}$. The diameters for Staphylococcus aureus were measured after $24 \mathrm{~h}$ respectively [12].

\section{Drug release kinetics}

Drug release kinetics was studied by curve fitting method to different kinetic models of zero order, first order, Higuchi and Hixson Crowell models to find out the mechanism of drug release, 60 $\%$ drug of release data was first fitted in the Korsmeyer-Peppas model and the value of ' $n$ ' the diffusion exponent was determined. According to this model if ' $n$ ' is b/w 0.45 to 0.5 the Fickian mechanism, 0.5 to 0.8 the Non-Fickian and if 0.8 to 1.0 Case-II transport i.e. a zero-order mechanism is governing the drug release mechanism from the gels [13].

\section{Statistical analysis}

All values presented in the study were an average of triplicate experiments for the same time points. Differences in viscosity in vitro drug release profile of moxifloxacin $\mathrm{HCl}$ in situ gel under different conditions were tested statistically using one-way analysis of variance (ANOVA) followed by Dunnett's test at the different level of significance. (†Statistically significant difference at $P<0.05$; ††statistically significant difference at $P<0.01$; †† †tatistically significant difference at $P<0.001$ from control) $[14,15]$.

\section{RESULTS AND DISCUSSION}

\section{Drug content}

The drug content of the sample was the range from $90 \%$ to $98 \%$ (table 2 ). The result indicated that the process employed to prepare gels in this study was capable of producing gels with uniform drug content.

\section{$p \mathbf{H}$}

All the formulation should have satisfactory $p \mathrm{H}$ ranging from 5.8 to 6.2 which is acceptable for ocular drug delivery (table 2).

\section{Measurement of phase change temperature}

The two main requirements of an in situ gelling system are viscosity and gelling capacity. The optimum thermosensitive in situ gel should have a gelation temperature higher than room temperature and a shift to gel at the conjunctival sac temperature $\left(35.0^{\circ} \mathrm{C}\right)$ after mixed with artificial tears. Based on the suitable range of gelation temperature $\left(25-35{ }^{\circ} \mathrm{C}\right)$, polaxomer chosen as the gelling agent. Polaxomer 407 is reported to be the less toxic of the commercially available polymer. It was found that increase in the concentration of polaxomer decreases the phase transition temperature. Modified chitosan in the range of $0.25,0.5$ and $0.75 \%$ did not affect the gelation temperature of formulation but it forms viscous formulation. The gelation temperature for the formulations was found between of $25.63 \pm 0.14{ }^{\circ} \mathrm{C}$ to $38.33 \pm 0.71{ }^{\circ} \mathrm{C}$. The minimum gelation temperature was observed for batch F9 that is $25.63 \pm 0.14$ ${ }^{\circ} \mathrm{C}$ (table 2). This might be an effect of higher concentration of polaxomer 407 (9\%) and with combination modified chitosan $(0.75 \%)$. In order to obtain an in-situ gel having increased mucoadhesiveness when modified chitosan was added into the formulation [8]. 


\section{Gelling capacity}

The formulation should have an optimum gelling capacity, so that after installation into the eye as a liquid (drops), it would undergo a rapid sol-to-gel transition and would preserve its integrity without dissolving or eroding for a prolonged period of time. Gelling capacity increases with increasing concentration of gelling agent both at higher and lower concentration of viscofying agent. Gelling capacity observed by visual observation. The gelation capacity data of prepared formulation presented in table 2 represent that the formulation F1, F2, F3 and F4 had gel after few minutes and dissolves rapidly. F5 and F6 had immediate gelation and underwent rapid dissolution. On the other hand the formulations F7, F8 and F9 had immediate gelation but exist for an hour [19]. This indirect that by increasing the concentration of polymer, transition time was decreased and the erosion time of formed gel was increased.

Table 2: Shows evaluation of in situ gel formulation

\begin{tabular}{llllll}
\hline Formulation code & pH & Drug content \% & Gelation temperature $\left({ }^{\circ} \mathbf{C}\right.$ ) & Gelling capacity & Viscosity (cps) \\
\hline F1 & $5.8 \pm 0.01$ & $94.2 \pm 0.6$ & $38.33 \pm 0.71$ & + & $264.3 \pm 5.9$ \\
F2 & $6.2 \pm 0.01$ & $95.1 \pm 1.04$ & $37.22 \pm 0.56$ & + & $281.3 \pm 3.71$ \\
F3 & $6.1 \pm 0.4$ & $92.1 \pm 0.33$ & $37.5 \pm 0.22$ & + & $354 \pm 7.51$ \\
F4 & $6.0 \pm 0.11$ & $95.1 \pm 0.12$ & $36.80 \pm 0.75$ & + & $426.3 \pm 7.84$ \\
F5 & $6.2 \pm 0.2$ & $98.8 \pm 0.2$ & $32.0 \pm 0.51$ & ++ & $444.6 \pm 10.3$ \\
F6 & $5.8 \pm 0.12$ & $94.6 \pm 0.1$ & $30.67 \pm 0.72$ & ++ & $568 \pm 11.4$ \\
F7 & $5.9 \pm 0.1$ & $92.4 \pm 0.14$ & $29.41 \pm 0.73$ & +++ & $772 \pm 10.5$ \\
F8 & $6.0 \pm 0.01$ & $90.7 \pm 0.33$ & $27.5 \pm 0.41$ & +++ & $875.6 \pm 8.69$ \\
F9 & $6.2 \pm 0.14$ & $96.2 \pm 0.01$ & $25.63 \pm 0.14$ & +++ & $986.3 \pm 6.39$ \\
\hline
\end{tabular}

Number of experiments=9, Each observation means is the mean \pm SD of three observations, + :gel after few minutes dissolves rapidly, $++:$ immediate gelation remains for few min, +++: immediate gelation remains for nearly an $\mathrm{h}$.

\section{Rheological studies}

For thermosetting gels, the viscosity at various conditions is an important rheological parameter involved in its utilization and its in vitro performance. For example, if viscosity is too high it will lead to difficult installation; on the contrary, if viscosity is too low it will give rise to increased drainage. Previous papers have shown that a polaxomer solution under non-physiological or physiological conditions demonstrated a Newtonian flow behaviour and that the shear increased linearly with an increase in shear rate. The viscosity values of all formulation were shown in table 2 . The formulations exhibited pseudoplastic rheology as evidenced by shear thinning and an increase in shear stress with increased angular velocity. Since the ocular shear rate is about $0.03 \mathrm{~s}^{-1}$ during inter-blinking periods and 4250-28500 $\mathrm{s}^{-1}$ during blinking. So, the viscoelastic fluids having high viscosity under low shear rates and low viscosity under high shear rates called as pseudoplastic fluid are often preferred [16]. Among all the formulation, F9 formulation provides maximum viscosity and statistically significant $(\mathrm{P}<0.01)$ value that is, $986.3 \pm 6.39 \mathrm{cps}$ at $100 \mathrm{rpm}$. The F1, F2 and F3 batch has a very low viscosity at $35^{\circ} \mathrm{C}$ that it did not improve the contact time of drug with eye. Batch F6, F7,F8, F9 containing $8 \%$ and $9 \%$ of polaxomer 407 and $0.25,0.5,0.75 \%$ modified chitosan showed very high viscosity that it forms a very stiff gel which may leads to the difficulty for installation and also retard the release of the drug.
Batch F4 and F5 showed good results but F5 showed better viscosity. Viscosity is an important factor to determine the residence time of drug in the eye [18]. The viscosity increased with increasing concentration of modified chitosan and polaxomer 407 was observed.

\section{In vitro drug release study}

The cumulative percent released versus time profiles of moxifloxacin $\mathrm{HCl}$ in situ gel containing polaxomer 407 and modified chitosan in different ratios are shown in fig. 2. The entire formulation containing $0.25 \%(\mathrm{w} / \mathrm{v})$ moxifloxacin $\mathrm{HCl}$. The in vitro drug release was ranging from $84 \%$ to $68 \%$ in $8 \mathrm{~h}$. The drug release from the batch $\mathrm{F} 6, \mathrm{~F} 7, \mathrm{~F} 8$,F9 having $8 \%$ and $9 \%$ polaxomer 407 and $0.25,05$ and $0.75 \%$ of modified chitosan showed a lesser cumulative percentage release in comparison to other formulations. The formulation $\mathrm{F} 5$ containing $8 \% \mathrm{w} / \mathrm{v}$ of polaxomer and $0.5 \%$ modified chitosan, showed a cumulative release of $92 \%$ at the end of $8 \mathrm{~h}$ which indicated that F5 provided sustained release. From in vitro drug release studies and gelation temperature for all formulations F5 showed sustained release up to $8 \mathrm{~h}$ and have gelation temperature closer to the ocular surface temperature that is $35^{\circ} \mathrm{C}$ hence the formulation was selected for further study [11]. The results are shown in fig. 1 showing statistically significant values $(\mathrm{P}<0.01)$ which indicate that the in vitro release from in situ gel of moxifloxacin $\mathrm{HCl}$ was sustained for $8 \mathrm{~h}$.

Table 3: Shows in vitro drug release

\begin{tabular}{|c|c|c|c|c|c|c|c|c|c|}
\hline Time h & F1 & F2 & F3 & F4 & F5 & F6 & F7 & F8 & F9 \\
\hline 0 & 0 & 0 & 0 & 0 & 0 & 0 & 0 & 0 & 0 \\
\hline 1 & 30.42 & 20.48 & 24.78 & 19.87 & 32.45 & 17.55 & 14.43 & 13.28 & 12.56 \\
\hline 2 & 42.51 & 31.76 & 32.54 & 26.6 & 45.8 & 24.56 & 27.76 & 22.67 & 20.43 \\
\hline 3 & 51.43 & 43.73 & 40.3 & 34.2 & 53.2 & 36.97 & 31.54 & 32.54 & 28.54 \\
\hline 4 & 66.15 & 54.27 & 48.45 & 43.85 & 68.43 & 47.34 & 42.43 & 45.76 & 36.89 \\
\hline 5 & 74.35 & 62.4 & 60.56 & 53.47 & 76.85 & 55.76 & 50.87 & 57.43 & 48.65 \\
\hline 6 & 79.32 & 69.46 & 68.97 & 61.43 & 82.45 & 63.78 & 62.94 & 59.55 & 52.84 \\
\hline 7 & 82.5 & 79.15 & 73.67 & 67.56 & 87.54 & 72.65 & 72.65 & 69.73 & 61.95 \\
\hline 8 & 84.21 & 82.45 & 80.9 & 78.4 & 92.56 & 78.43 & 78.43 & 72.54 & 68.4 \\
\hline
\end{tabular}

Number of experiments=9, mean in vitro drug release at $8 \mathrm{~h}$.

\section{Antibacterial study}

The optimized in situ gelling formulation showed antibacterial activity tested microbiologically by cup-plate technique. The antibacterial efficiency of the selected sustained release moxifloxacin $\mathrm{HCl}$ formulation F5 was calculated against staphylococcus aureus. The zones of inhibition of standard and ophthalmic formulation were found to be $24 \mathrm{~mm}$ and $21 \mathrm{~mm}$. The zone of inhibition of standard and ophthalmic formulation was found to be almost similar. The modified chitosan also showed a zone of inhibition of $18 \mathrm{~mm}$. The inhibition zones were evaluated after $24 \mathrm{~h}$ and reduction in the growth of microorganisms was clearly observed in fig. 2 . The zone of inhibition increased significantly as the amount of moxifloxacin $\mathrm{HCl}$ diffused from the in situ gel was increased [12]. 


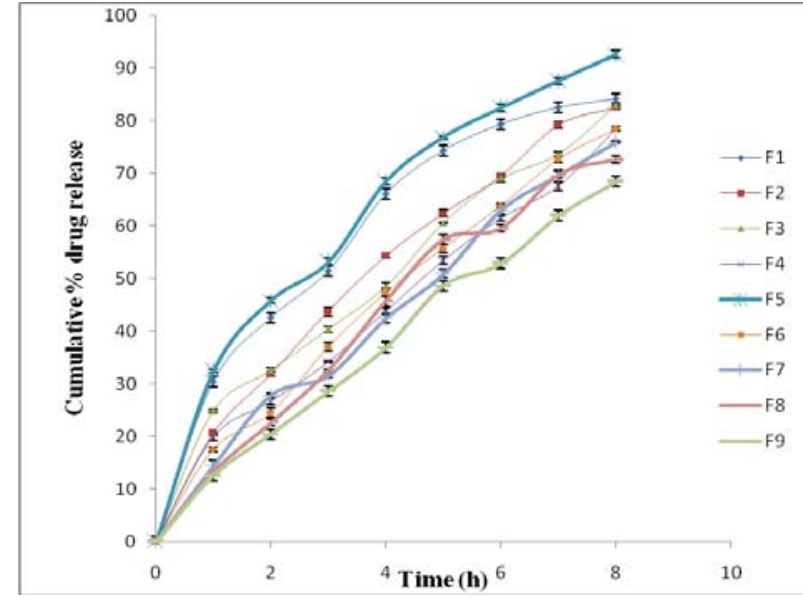

Fig. 1: In vitro dissolution profile of moxifloxacin $\mathrm{HCl}$ from in situ gelling system, number of experiments $=9$

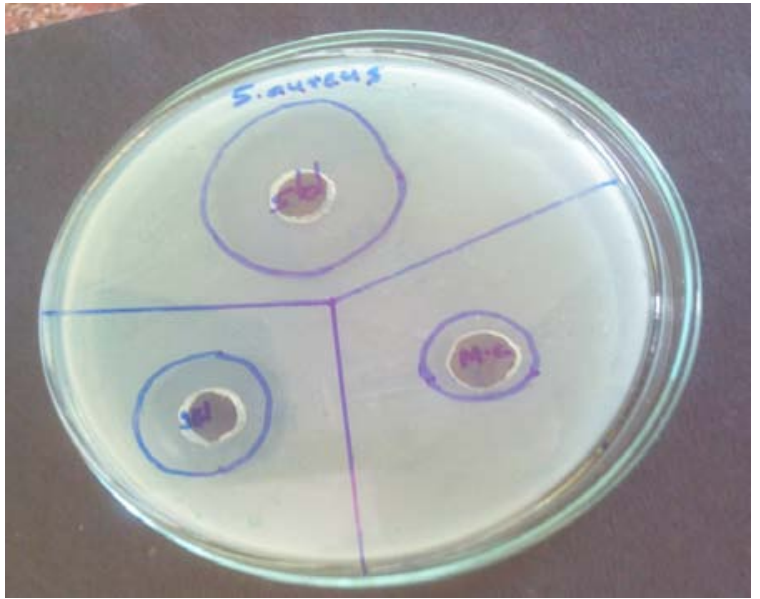

Fig. 2: Antimicrobial activity of standard, formulation and modified chitosan, number of experiments $=1$

Table 4: Antimicrobial activity of standard, formulation and modified chitosan

\begin{tabular}{llll}
\hline Microbial strain & Z0I (mm) Standard & Z0I (mm) F5 & Z0I(mm) Modified chitosan \\
\hline S. aureus & $24.2 \pm 0.45$ & $21.5 \pm 0.02$ & $18.4 \pm 0.26$ \\
\hline
\end{tabular}

Values are expressed as mean \pm SD of three observations

\section{Release kinetic}

The in vitro release profile was fitted to various kinetic models in order to find out the mechanism of drug release. The goodness of fit was evaluated using regression coefficient $\left(\mathrm{r}^{2}\right)$ values. To explore the drug release mechanism, in vitro release results were further fitted to the K-P equation. The regression coefficient $\left(\mathrm{r}^{2}\right)$ for all the formulations using different kinetics equation is listed in table 5 . The values of $\mathrm{r}^{2}$ for all formulations were found higher for Zero order model. It was found that all formulation mostly followed the zero order models as best fit model because of the higher value of $r$ (correlation coefficient). The release profile of in situ gelling formulations were treated with Korsmeyer Peppas equation and slope value $\mathrm{n}>0.85$ were indicating Case-II transport drug release involving non Fickian diffusion [17].

Table 5: Kinetics of in vitro drug release

\begin{tabular}{|c|c|c|c|c|c|c|c|}
\hline \multirow[t]{2}{*}{ Formulation } & \multirow{2}{*}{$\begin{array}{l}\text { Zero order } \\
\mathbf{r}^{2}\end{array}$} & \multirow{2}{*}{$\begin{array}{l}\text { First order } \\
\mathbf{r}^{2}\end{array}$} & \multirow{2}{*}{$\begin{array}{l}\text { Higuchi model } \\
\mathbf{r}^{2}\end{array}$} & \multirow{2}{*}{$\begin{array}{l}\text { Hixon crowell } \\
\mathbf{r}^{2}\end{array}$} & \multicolumn{2}{|c|}{ Korsmeyer-peppas } & \multirow{2}{*}{$\begin{array}{l}\text { Mechanism of drug } \\
\text { release }\end{array}$} \\
\hline & & & & & $\mathbf{r}^{2}$ & $\mathbf{N}$ & \\
\hline F1 & 0.994 & 0.911 & 0.974 & 0.959 & 0.991 & 0.94 & Case-II transport \\
\hline $\mathrm{F} 2$ & 0.995 & 0.88 & 0.975 & 0.944 & 0.993 & 0.873 & Case-II transport \\
\hline F3 & 0.968 & 0.981 & 0.983 & 0.986 & 0.993 & 0.905 & Case-II transport \\
\hline $\mathrm{F} 4$ & 0.994 & 0.93 & 0.984 & 0.974 & 0.989 & 0.869 & Case-II transport \\
\hline F5 & 0.994 & 0.855 & 0.978 & 0.941 & 0.992 & 1.054 & Case-II transport \\
\hline F6 & 0.99 & 0.902 & 0.967 & 0.953 & 0.986 & 0.941 & Case-II transport \\
\hline F7 & 0.94 & 0.939 & 0.97 & 0.973 & 0.997 & 0.892 & Case-II transport \\
\hline F8 & 0.993 & 0.939 & 0.97 & 0.971 & 0.987 & 0.863 & Case-II transport \\
\hline F9 & 0.994 & 0.911 & 0.966 & 0.959 & 0.987 & 0.841 & Non Fickian \\
\hline
\end{tabular}

Number of experiments $=9,{ }^{*}$ r-coefficient of correlation, n-kinetic constant

\section{Statistical analysis}

The results obtained from the experiment were statistically analyzed for response variables by using Graph Pad instat (version 3.1, Graph Pad Software Inc.). Statistical analysis (One way ANOVA) however revealed that batches were significantly different. Dunnett's multiple comparison tests predicted that there was a significant effect of concentration of polaxomer 407 and modified chitosan on the in vitro drug release and viscosity.

\section{CONCLUSION}

In this study, we suggest that the appropriate combination of polaxomer 407 and modified chitosan were suitable satisfactorily sustained the drug release from moxifloxacin $\mathrm{HCl}$ in situ gel, thereby potentially lowering corneal toxicity We demonstrated that poloxamer/modified chitosan formulation in a concentration of $8 / 0.5 \% \mathrm{w} / \mathrm{w}$ showed an optimal gelation temperature $\left(32^{\circ} \mathrm{C}\right)$ and was able to withstand low shearing forces at $35^{\circ} \mathrm{C}$. The gels proved to possess a mucoadhesive ability that is influenced by modified chitosan concentration. Therefore, the developed delivery system seems to be a promising tool for ophthalmic use, as it is easily administered and shows a prolonged ocular contact time.

\section{AUTHOR CONTRIBUTION}

Anuja Kadam developed a method, experimental part of work and writing of the manuscript. Pradnya Salunke is a technical executive in antibacterial activity research. Rahul Jadhav and Satwashila Kadam contributed in its manuscript correction.

\section{ACKNOWLEDGEMENT}

The authors would like to thank Dr. A. V. Yadav, Principal, Gourishankar Institute of Pharmaceutical Education and Research, Limb, Satara for providing the facilities to carry out this work and also for his valuable suggestions. I am also thankful to Chairman of Late Narayandas Bhawandas Chhabada Institute of Pharmacy, Raigaon, Satara for guiding and supporting us. 


\section{CONFLICT OF INTERESTS}

Declared none

\section{REFERENCES}

1. Rajeshwari NP, Rachana SK. In situ gelling system: a novel approach for ophthalmic drug delivery. World J Pharm Pharm Sci 2014;3:423-40.

2. Anshul S, Renu SA. Review on levofloxacin in the situ-gel formulation. Asian J Pharm Clin Res 2015;8:37-41.

3. Tais G, Guilherme MG, Eduardo MR, Sarmento VH, Freitas OD, Lopez RFV. A poloxamer/chitosan in situ forming gel with prolonged retention time for ocular delivery. Eur J Pharm Biopharm 2010;75:186-93.

4. Chaudhary B, Verma S. Preparation and evaluation of novel in situ gels containing acyclovir for the treatment of oral herpes simplex virus infections. Sci world J 2014:1-7. http:// dx.doi.org/10.1155/2014/280928.

5. Kumar S, Kavitha K, M Rupeshkumar, Jagadeesh Singh SD. Thermo and $\mathrm{PH}$ responsive ocular in situ gels formulation: based on combination with natural polymers. Am J Pharmtech Res 2013;3:290-301.

6. Mandal S, Thimmasetty MKMJ, GL Prabhushankar, MS Geetha. Formulation and evaluation of an in situ gel-forming ophthalmic formulations of moxifloxacin hydrochloride. Int J Pharm Investig 2012;2:78-82.

7. Wagh VD, Deshmukh KH, Wagh KV. Formulation and evaluation of in situ gel drug delivery system of sesbania grandiflora flower extract for the treatment of bacterial conjunctivitis. Pharm Sci Res 2012;4:1880-4.

8. Bhoyar BS, Agnihotri VV, Bodhankar MM. Design of polyoxyethylene-polyoxypropylene block co-polymer based in situ gelling system for localized ocular drug delivery. Int J Res Pharm Chem 2011;1:591-600.
9. Swamy SP, Sanjeri F, Nadaf A, Jamakandi VG, Mulla JS. Formulation and evaluation of a novel in situ gum based ophthalmic drug delivery system of linezolid. Sci Pharm 2007;76:516-32.

10. Reddy JS, Ahmed MG. Sustained ocular delivery of sparfloxacin from $\mathrm{pH}$ Triggered in situ gelling system. Mahidol Univ J Pharm Sci 2013;40:16-25.

11. Sampathi S, Sharma J, Kaur R, Saini V. Design development and characterization: in situ gel of lomefloxacin hydrochloride for ocular drug delivery. World J Pharm Sci 2014;3:2350-64.

12. Sharma A. Development and characterization of in situ oral gel of spiramycin. BioMed Res Int 2014:1-7. http:// dx.doi.org/10.1155/2014/876182

13. Saxena P, Swatantra KS, Kyshwaha. PH sensitive hydrogel of levofloxacin hemihydrate for opthalmic drug delivery. World J Pharma Res 2014;3:4003-21.

14. Pawar P, Kashyap H, Malhotra S, Sindhu R. Hp- $\beta$-CDVoriconazole in situ gelling system for ocular drug delivery: in vitro, stability, and antifungal activities assessment. BioMed Res Int 2013:1-9. http://dx.doi.org/10.1155/2013/341218

15. Kanoujia J, Sonker K, Pandey M, Kymonil KM, Saraf SA. Formulation and characterization of a novel ph-triggered in-situ gelling ocular system containing gatifloxacin. Int Curr Pharm J 2012;4:34-43.

16. Hongyi Q, Wenwen C, Chunyan H, Chuming C, Wenmin L, Chunjie W. Development of a poloxamer analogs/carbopolbased in situ gelling and mucoadhesive ophthalmic delivery system for puerarin. Int J Pharm 2007;337:178-87.

17. Reddy RK, M Srinivas, R Srinivas. Once-daily sustained-release matrix tablets of nicorandil: Formulation and in vitro evaluation. AAPS PharmSciTech 2003;4:480-8.

18. Maheswaran A, Padmavathy J, Nandhini V, Saravanan D, Angel P. Formulation and evaluation of floating oral in situ gel of diltiazem hydrochloride. Int J Appl Pharm 2017;9:50-3.

19. Laddha UD, Mahajan HS. An insight to ocular in situ gelling systems. Int J Appl Pharm 2017;6:31-40. 